\title{
MORPHOFUNCTIONAL CHARACTERISTICS OF ILEAC ATRESIA IN NEWBORNS
}

\section{O.P. Antoniuk}

Abstract. The morphological indicators have been determined and functional abnormalities of the mucosa, muscular membrane, intermuscular nervous plexus, vessels of wall in preatretic, atretic and postatretic segments of ileum have been identified. The ability of the intestine to anastomoses in pathogenic type of atresia with primary disorders of vascular development was evaluated. We recommend resection of visually unchanging part of the intestine above of preatretic and below of postatretic segments of intestine to the nearest level of the iliocolic arteries.

Key words: morphometry, atresia, ileum, human.

Bukovinian State Medical University (Chernivtsi)

Рецензент - проф. О.М. Слободян

Buk. Med. Herald. - 2015. - Vol. 19, № 2 (74). - P. 3-7

Надійшла до редакції 13.01.2015 року

(C) О.П. Антонюк, 2015

УДК 616-089.23-77.001.36

Е.Д. Бабов, Т.Б. Херсонская, Н.А. Борченко

\section{СРАВНИТЕЛЬНЫЙ АНАЛИЗ УСПЕШНОСТИ ФУНКЦИОНИРОВАНИЯ ОРТОДОНТИЧЕСКИХ МИКРОИМПЛАНТОВ И МИНИПЛАСТИН}

Одесский национальный медицинский университет, г. Одесса

Резюме. В статье приведен сравнительный анализ выживаемости ортодонтических микроимплантов и минипластин в зависимости от пола, возраста, гигиены полости рта. Показано, что частота осложнений при применении микроимплантов была достоверно выше,

Введение. Определение того, насколько успешным будет функционирование микроимплантов и минипластин в каждом конкретном клиническом случае, является критически важным для выбора плана их установки, величины.

Цель исследования. Сравнительная оценка функционирования устройств для временного анкоража (микроимплантов и минипластин) в зависимости от пола и возраста пациентов, а также уровня гигиены полости рта.

Материал и методы. В исследование было включено 49 микроимплантов и 18 минипластин, установленных у 34 пациентов возрастом от 14 до 42 лет. Включенным в исследование пациентам устанавливались микроимпланты и минипластины I-плант (Украина, Свидетельство о госрегистрации 13887/2014). Статистическая обработка полученных данных производилась при помощи программного обеспечения IBM SPSS Statistics 20.0 (Armonk, NY, USA) и MS Excel 2003.

Результаты исследования и их обсуждение. Результаты функционирования устройств для временного анкоража на протяжении периода их использования отражены в таблице 1 .

При оценке успешности функционирования обоих типов устройств для временного анкоража нами была применена условная градация. Полностью успешным функционированием мы считали такое, при котором не наблюдалось ни наруше- чем при применении минипластин. Функционирование микроимплантов было более зависимым от указанных факторов, особенно от гигиены полости рта.

Ключевые слова: микроимплант, минипластина, выживаемость, осложнения, гигиена.

ния фиксации устройства, ни воспалительного процесса в зоне окружающей его рабочую часть слизистой оболочки. Для включенных в исследование микроимплантов частота успешного функционирования составила 67,4 \%, а для минипластин $-77,8 \%$. В то же время в некоторых клинических случаях мы наблюдали сохранение фиксации устройства при развитии такого воспалительного процесса. Такое функционирование оценивалось нами как условно успешное. Оно наблюдалось у 22,4 \% установленных микроимплантов и 22,2 \% минипластин. Необходимо отметить, что, как правило, в этих случаях рабочая часть устройства располагалась в зоне подвижной слизистой оболочки, что будет детально рассмотрено далее. Дезинтеграция установленных микроимплантов наблюдалась в 10,2 \% случаев. Дезинтеграции минипластин мы не наблюдали. На наш взгляд, условно успешное функционирование микроимплантов и минипластин можно оценивать как позитивный результат, поскольку воспаление окружающей слизистой оболочки в этих случаях было обратимым при применении соответствующего лечения, а стабильность устройств при этом не была нарушена, что позволяло и дальше использовать их в качестве ортодонтической опоры. Итак, если оценивать условно успешное функционирование микроимплантов и минипластин как позитивный результат, в целом 
Результаты функционирования устройств для временного анкоража у пациентов исследуемой выборки

\begin{tabular}{|c|c|c|}
\hline Результаты & Микроимпланты (49) & Минипластины (18) \\
\hline Успешное функционирование & $67,4 \%(33)$ & $77,8 \%(14)$ \\
\hline $\begin{array}{c}\text { Воспаление маргинальной слизистой } \\
\text { оболочки, устройство стабильно }\end{array}$ & $22,4 \%(11)$ & $22,2 \%(4)$ \\
\hline Потеря устройства & $10,2 \%(5)$ & - \\
\hline Успешное функционирование, всего & $89,8 \%(44)$ & $100,0 \%(18)$ \\
\hline
\end{tabular}

Таблица 2

Корреляционный анализ успешного функционирования устройств для временного анкоража, пола и возраста пациентов с применением непараметрического коэффициента - $\rho$ Спирмена

\begin{tabular}{|c|c|c|c|}
\hline \multicolumn{2}{|c|}{} & Пол & Возраст \\
\hline \multirow{3}{*}{ Микроимпланты } & $\rho$ Спирмена & $0,402^{*}$ & $0,563^{*}$ \\
\cline { 2 - 4 } & Значение (2-ст) & 0,043 & 0,032 \\
\cline { 2 - 4 } & $\mathrm{N}$ & 49 & 49 \\
\hline \multirow{3}{*}{ Минипластины } & $\rho$ Спирмена & 0,344 & 0,412 \\
\cline { 2 - 4 } & Значение (2-ст) & 0,071 & 0,057 \\
\cline { 2 - 4 } & $\mathrm{N}$ & 18 & 18 \\
\hline
\end{tabular}

Примечание. * - значения достоверны, $\mathrm{p}<0,05$

Таблица 3

Корреляционный анализ успешного функционирования устройств для временного анкоража, пола и возраста пациентов с уровнем гигиены полости рта применением непараметрического коэффициента - $\rho$ Спирмена

\begin{tabular}{|c|c|c|c|c|}
\hline \multicolumn{2}{|c|}{} & Пол & Возраст & Гигиена \\
\hline \multirow{2}{*}{ Микроимпланты } & р Спирмена & $0,402^{*}$ & $0,563 *$ & $-0,601 * *$ \\
\cline { 2 - 5 } & Значение (2-ст) & 0,043 & 0,032 & 0,005 \\
\hline \multirow{2}{*}{ Минипластины } & р Спирмена & 0,344 & 0,412 & $-0,432$ \\
\cline { 2 - 5 } & Значение (2-ст) & 0,071 & 0,057 & 0,051 \\
\hline \multirow{2}{*}{ Гигиена } & р Спирмена & $0,631 * *$ & $0,712^{* *}$ & 1 \\
\cline { 2 - 5 } & Значение (2-ст) & 0,002 & 0,001 & \\
\hline
\end{tabular}

Примечание. * - значения достоверны, $\mathrm{p}<0,05 ; * *-\mathrm{p}<0,01$

функционирование микроимплантов можно было считать успешным в 89,8 \% случаев, а минипластин - в $100 \%$ случаев.

Для оценки зависимости успешности функционирования обоих видов устройств для временного анкоража от выбранных общих и местных факторов нами применялся линейный корреляционный анализ. В первую очередь мы оценивали зависимость успешного функционирования микроимплантов и минипластин от пола и возраста. Результаты приведены в таблице 2.

Данные, приведенные в таблице 2 показывают, что успешность функционирования микроимплантов оказалась зависимой как от пола пациентов, так и от их возраста. У пациентов мужского пола осложнения развивались достоверно чаще. Кроме того, частота осложнений снижалась с возрастом. Однако, эти тенденции не относились к успешности функционирования минипластин, где мы не выявили достоверной корреляции ни с полом, ни с возрастом пациентов.

Почему же пол и возраст пациентов влияют на функционирование микроимплантов, однако никак не связаны с функционированием минипластин? Мы предположили, что, возможно, пол и возраст влияют на интеграцию микроимплантов опосредованно. Вероятным фактором, который мог бы непосредственно влиять на функционирование микроимплантов и был бы связан с полом и возрастом, на наш взгляд, мог быть уровень гигиены полости рта. Для проверки этого предположения у пациентов исследуемой выборки был определен упрощенный индекс гигиены полости рта Грина-Вермильона и вычислена его корреляция с полом, возрастом, а также развитием осложнений при функционировании микроим- 
плантов и минипластин. Результаты корреляционного анализа представлены в таблице 3.

Как можно видеть из приведенной таблицы 3 , уровень гигиены полости рта достоверно коррелировал с полом и, еще более сильно, с возрастом. Это объясняет зависимость выживаемости микроимплантов от возраста и от пола, которые в данном случае являются косвенными признаками. Что касается прямой взаимосвязи выживаемости микроимплантов и минипластин с уровнем гигиены полости рта, у минипластин такой корреляции обнаружено не было, в то время как при применении микроимплантов она была достоверной и сильной.

Причины меньшей зависимости функционирования минипластин от приведенных факторов, на наш взгляд, объясняются их изолированностью от полости рта и лучшей по сравнению с микроимплантами фиксацией. В то же самое время, относительно небольшие размеры микроимплантов и непосредственный контакт зоны их фиксации со слизистой оболочкой полости рта, на наш взгляд, ухудшают прогноз их выживаемости в пограничных случаях.

\section{Выводы}

1. Частота осложнений интеграции и функционирования микроимплантов была достоверно выше, чем при применении минипластин, и со- ставляла 32,6 \% по сравнению с 22,2 \% при применении минипластин. Из них в 10,2 \% случаев наблюдалась потеря микроимплантов, в то время как нарушения интеграции минипластин не наблюдалось.

2. Стабильность микроимплантов достоверно коррелировала с полом, возрастом пациентов и уровнем гигиены полости рта, в то время как при применении минипластин такой взаимосвязи не наблюдалось.

Перспективы дальнейших исследований. Дальнейшие исследования факторов, влияющих на стабильность микроимплантов и минипластин, позволят выделить важнейшие из них и уточнить показания к применению конкретного вида устройств для анкоража в конкретном клиническом случае.

\section{Литература}

1. The use of microimplants in orthodontic anchorage / C.H. Chen, C.S. Chang, C.H. Hsieh [et al.] // J. Oral. Maxillofac Surg. - 2006. - Aug. - № 64 (8). P. 1209-1213.

2. Systematic review of the experimental use of temporary skeletal anchorage devices in orthodontics / M.A. Cornelis, N.R. Scheffler, H.J. De Clerck [et al.] // Am. J. Orthod. Dentofacial Orthop. - 2007. - Apr. - № 131 (4 Suppl). - P. 52-58.

3. Motoyoshi M. Clinical indices for orthodontic miniimplants / M. Motoyoshi // J. Oral. Sci. - 2011. - Dec. № 53 (4). - P. 407-412.

\section{ПОРІВНЯЛЬНИЙ АНАЛІЗ УСПІШНОСТІ ФУНКЦІОНУВАННЯ ОРТОДОНТИЧНИХ МІКРОІМПЛАНТІВ ТА МІНІПЛАСТИН}

\section{Є.Д. Бабов, Т.Б. Херсонська, Н.А. Борченко}

Резюме. У статті наведено порівняльний аналіз успішності функціонування ортодонтичних мікроімплантів та мініпластин залежно від статі, віку та гігієни порожнини рота. Показано, що частота ускладнень при застосуванні мікроімплантів була достовірно вищою, ніж при застосуванні мініпластин. Функціонування мікроімплантів було також більш залежним від вказаних факторів, особливо від гігієни порожнини рота.

Ключові слова: мікроімплант, мініпластина, успішність функціонування, ускладнення, гігієна.

\section{SUCCESS RATE OF ORTHODONTIC MICROIMPLANTS AND MINIPLATES: COMPARATIVE ANALYSIS}

\section{E.D. Babov, T.B. Khersonskaya, N.A. Borchenko}

Abstract. Comparative analysis of success rate of orthodontic microimplants and miniplates is given according to age, sex and oral hygiene level. Success rate of microimplants appeared to be significantly lower compared to miniplates. Following factors also appeared to influence microimplants success rate more than miniplates.

Key words: microimplant, miniplate, success rate, complications, oral hygiene.

National Medical University (Odessa)

Рецензент - проф. О.Б. Бєліков
Buk. Med. Herald. - 2015. - Vol. 19, № 2 (74). - P. 7-9

Надійшла до редакції 10.03.2015 року

(С Е.Д. Бабов, Т.Б. Херсонская, Н.А. Борченко, 2015 